\section{First, the bad news...}

$\mathrm{P}$ hysicians are schooled in the art of breaking bad news on an individual basis: the sudden bereavement, the terminal diagnosis, the ominous test result. Gone is the paternalistic impulse to spare patients from horrible truths. Physicians are also advised to admit error, when it occurs: to explain promptly and frankly when things go wrong. These standards of disclosure rest on the premise that patients have a right to be informed about their own situation.

Does that collective entity, the public, not also have "the right to know"?

Unfortunately, in matters affecting public health there is a long tradition of parcelling out the truth to a public credited with the thick-headed, panic-prone intelligence of a herd. Granted, risk communication is a subtle art: how do we persuade the public to adopt needed changes in behaviour without provoking undue anxiety or compensatory behaviours that introduce new risks? From bovine spongiform encephalopathy, to PCBs in breast milk, to West Nile virus, the communication of risk begs for its own risk assessment. ${ }^{1}$ One strategy that we have heard mooted lately is to warn the public only of important risks that they can actually take measures to avoid.

Some would have us believe that the public did not need to know about the outbreak of Clostridium difficile-associated diarrhea $(\mathrm{CDAD})$ occurring in hospitals in Montréal and elsewhere. After news of the situation broke in this journal, ${ }^{2}$ one hospital administrator and Quebec's minister of health told the press that $C$. difficile infection was a hospital matter and nothing out of the ordinary. The latter said his Ministry had known about it for some time - the only change was that news reports were arousing concern.

This nonchalance is astounding, but it is true that the $C$. difficile story is a two-in-one. First, it is about the evidence that something new and alarming is going on: it appears that rates of CDAD are increasing, and that the disease is becoming more virulent. ${ }^{3}$ For this part of the story, the issues and the way forward are clear, even if they are not simple. We need better surveillance and reporting of nosocomial infectious disease; we need collaboration between hospital infection control and public health; we need to rationalize the use of antibiotics and to consider other possible risk factors (such as PPIs); ; we need better hospital hygiene and infrastructure upgrades to make this possible $;^{3,5,6}$ we need more research, including the genetic mapping of the organism and comparison with earlier subtypes.

The second part of the story is about public disclosure. Here, we need a change of attitude. Hospitals are publicly funded institutions, organized to serve the public. It follows that the public has a right to know both in general and, at times, specific terms what is happening in those institutions. How many Canadians are aware of their risk of acquiring an infection in hospital - a risk that a recent survey by the Canadian Institute for Health Information puts at 1 in 9? $?^{7}$ Some American states, lead by Illinois last year, have been making the tracking and public reporting of nosocomial infection rates a matter of law, to improve consumer choice and provide an incentive for change.

The data on C. difficile in Canadian hospitals are imperfect - but, to be effective, public health interventions cannot wait for perfect data. There is no time, and no excuse, for nannyism. ${ }^{8}$ Patients who know they are faced with an outbreak like this one can make more informed choices as to where, if and when they consent to elective surgery. Patients, staff and visitors in hospitals might be more attentive to hand and toilet hygiene and contact with other patients. Patients leaving the hospital, particularly those at increased risk (i.e., those going home on antibiotics, or elderly or immunosupresssed patients), might be more alert to warning signs of fever or diarrhea.

But there is a third part to the story, which we can write about only in outline. It is the part about physicians who hesitate to speak out when difficult situations arise in their hospitals. It is about those who make dark jokes about job security when they wade publicly into scientific controversy. It is about clinicians and trainees on the wards who, troubled by the ethics of exposing patients to undisclosed risks, have struggled to get an honest discussion started about $C$. difficile. In a bad-news story, the stifling of concerned voices on the front lines of medicine may be the worst news of all. — CMAF

\section{References}

1. Powell D, Leiss W. Mad cows and mother's milk: the perils of poor risk communication. Montréal and Kingston: McGill-Queen's University Press; 1997.

2. Eggertson L, Sibbald B. Hospitals battling outbreaks of C. difficile. CMAJ 2004;171(1):19-21.

3. Valiquette L, Low DE, Pépin J, McGeer A. Clostridium difficile infection in hospitals: a brewing storm. CMA7 2004;171(1):27-9.

4. Dial S, Alrasadi K, Manoukian C, Huang A, Menzies D. Risk of Clostridium difficile diarrhea among hospital inpatients prescribed proton pump inhibitors: cohort and case-control studies. CMA7 2004;171(1):33-8.

5. Louie TJ, Meddings J. Clostridium difficile infection in hospitals: risk factors and responses [editorial]. CMA7 2004;171(1):45-6.

6. Loo VG, Libman MD, Miller MA, Bourgault AM, Frenette CH, Kelly M, et al; Clostridium difficile Associated Diarrhea Clinical Study Investigators Group. Clostridium difficile: a formidable foe [editorial]. CMA7 2004;171(1):47-8.

7. Canadian Institute for Health Information. Health Care in Canada, 2004. Ottawa: The Institute; 2004.

8. From nannyism to public disclosure: the BSE inquiry report [editorial]. CMA7 2001;164(2):165. 